\title{
Evaluation of the Intrinsic Performance of Electrical-Resistance Units for Measuring Soil Moisture
}

\author{
Modesto Capiel
}

\section{INTRODUCTION}

Irrigation should be efficient and timely if it is expected to be productive. Crop yields are closely associated with plant-water relations under a given soil and climatic environment. The lack of adequate soil moisture, necessary to maintain plant turgescence and growth, cannot be guessed satisfactorily before the plant shows signs of internal water deficit that may impair vegetative growth and reduce crop yields.

Soil-moisture-potential measuring devices are useful to detect the energy status of water in the soil, and consequently, the relative availability of soil water for plant needs. If the devices are characterized by sensitivity, precision, and uniformity, they may be used reliably to determine when to start and when to stop irrigation without entering into water-volume considerations.

Tensiometers and electrical-resistance plaster units are the most commonly known devices used to evaluate the energy status of water in the soil. Tensiometers have the advantage over plaster units of being more sensitive in the wet range of soil moisture and requiring no calibration. Plaster units cover a wider range of available soil moisture, are cheaper, require no servicing, and their low cost allows for more replication to compensate for soil moisture differences with locations and depths.

In order to recognize properly the physical characteristics of soil moisture blocks, intimately related to their performance in situ a study is indicated to evaluate the intrinsic behavior of the blocks as soil-moisture-potential indicators, independently of a surrounding soil.

\section{REVIEW OF LITERATURE}

Different varieties of materials, sold under such names as "gypsum," "plaster of paris," and "Hydrocal" have been employed in the construction of plaster blocks. They seem to exhibit differences in both their chemical and physical characteristics. When Bouyoucos and Mick (5) ${ }^{2}$ developed

${ }^{1}$ Associate Soil Scientist, Gurabo Substation, Agricultural Experiment Station, University of Puerto Rico, Río Piedras, P.R. The author wishes to acknowledge the valuable encouragement offered by correspondence by Dr. George J. Bouyoucos, professor emeritus of Soil Science, Michigan State University, East Lansing, Mich.

${ }_{2}^{2}$ Italic numbers in parentheses refer to Literature Cited, p. 367. 
the first plaster electrical-resistance unit to determine the water potential of the soil they found that the electrical resistance of the block began to change only when moisture was lost from the block to the extent that air filled some part of the pore space. This condition appeared to exist as the field capacity of the soil was approached. This lack of sensitivity at the higher level of soil moisture has been the main criticism of the application of the blocks for field use.

Bouyoucos (3) indicated that gypsum plaster blocks become slightly, but definitely more sensitive to moisture changes in the soil by using stainless steel screen-type electrodes instead of the conventional copper leads. In addition, he claimed that his new screen-type electrode developed minimum stray currents. Bourget et al. (2) reported from a laboratory evaluation of various types of plaster units that the Bouyoucos (3) units exhibited the best uniformity and greatest sensitivity above 0.3 atmosphere. Below this value it was found that the units had too little sensitivity to be useful.

Lately, Bouyoucos (4) has reported that it is possible to increase significantly the sensitivity of pure gypsum plaster blocks by increasing the pore space in the blocks. Blocks with equal parts of gypsum and water increased the water-holding capacity of the units from 32 to 57 percent. Originally, the proportion of water used in the mix was 66 percent that of gypsum. Bouyoucos claimed that, in addition to increasing the water:gypsum ratio, the greater sensitivity of the blocks was accomplished by moist curing of the blocks and different arrangement of the screen-type electrodes.

Perrier and Marsh (8) reported that Hydrocal B-11, compared to casting plaster, Hydrostone, and Hydrocal White, was generally superior as to weathering, sensitivity, and change of resistance due to changes in density. Capiel (6) observed that the concentric electrodes plugs ${ }^{3}$ made with Hydrocal B-11, 6 parts water to 10 parts plaster, exhibited better precision and greater sensitivity than gypsum casting plaster.

Other physical characteristics affect the performance of moisture blocks. Their lag in response to soil-moisture changes might cause erroneous conclusions unless this fact is recognized. Taylor (10) indicated that this lag might be reduced when the moisture capacity of the unit was small, and the transmission of water across the contact boundary between the unit and the soil rapid.

Uniformity and precision are other desirable characteristics of moisture blocks. Kelly et al. (7) said that it was important that the pore-size distribution of all blocks be very similar because water drains faster from the larger pores at lower tensions (higher water potential) than from smaller pores. Anderson and Edlefsen (1) suggested that, to ensure unquestioned simi-

s Manufactured by Rayturn Corp., Portland, Oreg. Endorsement of these instruments is not implied. 
larity in characteristics of the blocks, such factors as mix-proportion, mixing time, and pouring time must be carefully reproduced in the construction of each block. As Tanner et al. (9) stated, satisfactory use of blocks to indicate field capacity, first wilting, and time-to-irrigate requires that the resistance value of the blocks be within reasonably close agreement with each other for any given level of moisture availability. They observed that when testing the blocks for uniformity in their initial reading, blocks were more uniform when wetted under vacuum than by capillarity or plunging.

\section{EXPERIMENTAL PROCEDURE}

Various types of electrical-resistance units, varying in the kind of matrix material, mix preparation, form and arrangement of the electrodes, and in the geometry of the units, were constructed in the laboratory. These units were tested for sensitivity, uniformity, and precision; on the basis of their performance the most promising units were subsequently subjected to a final comparison. The Bouyoucos commercial units ( $(3)$ were included to make a relative evaluation of the laboratory-constructed units.

A platinized nickel rod coated with platinum black ${ }^{4}$ was used to make electrodes of some of the units, and stainless steel screen, also coated with platinum black, was used on others.

The following types of units were constructed and included in the preliminary study:

1. Rectangular block $1916 \times 1 \% 16 \times 1 / 2$ inches, made from Hydrocal B-11 mixed with hot distilled water. Mix proportion is 7 parts water to 10 parts Hydrocal. Electrodes were made stainless steel $(20 \times 20$ mesh) $15 / 16 \times 1 / 4$ inch in size, located symmetrical with respect to the block at $1 / 4$ inch separation.

2. Rectangular block similar to No. 1, but made with water at room temperature.

3. Rectangular block similar to No. 1, except that a vibrator, instead of tapping was used to remove the entrapped air in the mix after it was poured into the mold.

4. Rectangular block differing from No. 3 in that the electrodes were made from a fine-mesh screen (about $100 \times 100$ mesh), and were impregnated with platinum black.

5. Rectangular block $15 / 16 \times 27 / 16$ inches, made from Hydrocal B-11. Mix proportion was 2 parts distilled water to 3 parts Hydrocal. Electrodes were made from platinized nickel rod, impregnated with platinum black $21 \% 6$ inches long by 36 inch in diameter. They were located parallel and $7 / 8$ inch apart.

6. Rectangular block differing from No. 2 in that the mix proportion was made 2 parts water to 3 parts Hydrocal. The electrodes were impregnated with platinum black.

7. Bouyoucos block ( $(s)$, impregnated with nylon resin.

8. Bouyoucos block (s), not impregnated.

9. Rectangular block, similar to No. 1, except that these units were made with

- Supplied by Industrial Instruments, Inc., Cedar Grove, N.J. No endorsement is intended. 
platinized nickel-rod electrodes impregnated with platinum black, $\% 16$ inch long by 1/8 inch in diameter.

10. Cylindrical type of block, $13 / 8$ inches long by $7 / 8$ inch average diameter, made from Hydrocal B-11 and distilled hot water. Mix proportion was 7 parts water to 10 parts Hydrocal. The electrodes were located concentric and made from stainless steel screen $(20 \times 20 \mathrm{mesh}), 3 / 16$-inch separation. Inner and outer electrodes have $1 / 8$ inch and $1 / 2$ inch diameter, respectively.

11. Cylindrical block similar to No. 10, but made with water at room temperature.

12. Cylindrical block similar to No. 10, except that the inner concentric electrode was made from platinized nickel rod, $9 / 16$ inch long, impregnated with platinum black. Outer electrode was made from stainless steel screen $(20 \times 20$ mesh), $5 / 16$ inch long by 1/2 inch in diameter.

13. Rectangular block similar to No. 1, except that it was constructed with gypsum molding plaster No. 1 and distilled water at room temperature.

Each of the above-described moisture blocks will be mentioned from now on by their numbers as given above.

Six types of blocks were included in the final comparison. Two of them correspond with units 2 and 7 of the preliminary study. The others were constructed with some modifications found necessary in the preliminary study. The units included in the final study are identified by the preceding numbers as follows:

1. This was a rectangular block described as No. 2 in the preliminary study.

2. Rectangular block $1 \% / 6 \times 13 / 16 \times 1 / 2$ inches. Made from gypsum molding plaster with equal parts of distilled water to plaster. The electrodes were made from $20 \times 20$ mesh, stainless steel screen, $15 / 16$ by $1 / 4$ inch, located centrally and symetrically with respect to the block, at $1 / 4$-inch separation between the electrodes.

3. Cylindrical type of block $13 / 8$ inches long by $7 / 8$-inch mean diameter. Made from Hydrocal B-11, 3 parts distilled water to 5 of plaster. Electrodes were located concentric to each other and were $1 / 8$ and $1 / 2$ inch in diameter. They were made from stainless steel, $20 \times 20$-mesh screen.

4. Cylindrical block similar to No. 3 above, except that the mix proportion was 4 parts distilled water to 5 of plaster.

5. Rectangular block similar to No. 1, except that the electrodes were made from platinized nickel rod coated with platinum black, and that the mix proportion was 4 parts distilled water to 5 parts plaster.

6. Bouyoucos block, impregnated with nylon resin, described as No. 7 before.

An attempt was made to evaluate the intrinsic sensitivity and precision of the moisture blocks, independently of the nature and degree of contact of the block with surrounding soil. The block water-potential at increasing time intervals was obtained from a mercury manometer tensiometer located centrally with respect to the blocks in a small compartment. Both blocks and the tensiometer were exposed to the same evaporative demand of the air, starting from saturation. Thus, it was the accumulated drying power of the air surrounding the blocks and the tensiometer, which established 
the block water-potential after a given time interval and, as indicated by the tensiometer.

The electrical-resistance reading of the blocks was obtained whenever a block water-potential was taken with increasing time intervals. As tensiometers are not reliable below a water-potential of around $-75 \mathrm{j} . / \mathrm{kg}$. $^{5}$ it was decided to evaluate the soil-moisture desorption curves of the blocks within the tensiometer range, at around $0,-35$, and $-65 \mathrm{j} . / \mathrm{kg}$., and at $0,-10,-25,-35,-50$ and $-65 \mathrm{j} . / \mathrm{kg}$. for the preliminary and the final studies, respectively. In addition, the amount of water released by the blocks at decreasing block water-potentials was measured for the different units in the final study. This latter study was carried further beyond the range covered by a tensiometer, electrical-resistance readings and percentage moisture of the block by weight being taken simultaneously at this time. The weight of the electrodes plus that of the connected insulated wire was substracted from the weight of each block.

\section{RESULTS}

\section{PRELIMINARY WORK}

Table 1 indicates the results obtained in the preliminary study as related to the uniformity of the blocks (coefficient of variability). It does not appear that the use of hot distilled water to prepare the mix, or the use of a vibrator during the settling time, instead of using water at room temperature, or tapping the mix after pouring, respectively, appreciably increased the uniformity of the blocks. The use of fine-mesh screen (100 x 100 mesh) instead of $20 \times 20$-mesh stainless steel screen, appears to have reduced the uniformity of moisture-block readings with decreasing block water-potential.

Platinized nickel rod coated with platinum black, when used as electrode instead of stainless steel screen, appeared somewhat to increase the uniformity of rectangular blocks. Platinum-black coating did not appear to reduce significantly (table 2 ) the influence of external contact on moisture block readings. However, a cylindrical or coaxial design of the blocks appeared to counteract the effect of external contact above that of a rectangular design. (table 2).

It is apparent from table 3 that cylindrical moisture plugs exhibit greater sensitivity (steeper slope) than rectangular units. Bouyoucos blocks appeared to be significantly less sensitive and precise than the laboratoryconstructed units made from Hydrocal B-11.

$61 \mathrm{j} . / \mathrm{kg}$. is equivalent to $1 \times 10^{4} \mathrm{ergs} / \mathrm{gm}$., or $10.17 \mathrm{~cm}$. of water tension or suction units when the density of water is $1 \mathrm{gm} . / \mathrm{cm}^{3}$ 
TABLE 1.-Relative uniformity as indicaled by the coefficient of variation and the standard deviation, up to around $-70 j . / \mathrm{kg}$., of various kinds of electrical resistance units tested in the laboratory

\begin{tabular}{|c|c|c|c|c|c|c|c|c|c|c|c|}
\hline \multirow{3}{*}{$\begin{array}{l}\text { Identifi- } \\
\text { cation } \\
\text { No.2 }\end{array}$} & \multirow{3}{*}{ Blocks } & \multirow{3}{*}{ Readings } & \multicolumn{9}{|c|}{ Block water potential } \\
\hline & & & \multicolumn{3}{|c|}{ Up to $-5 \mathrm{j} . / \mathrm{kg}$. } & \multicolumn{3}{|c|}{ From -35 to $-40 \mathrm{j} . / \mathrm{kg}}$. & \multicolumn{3}{|c|}{ From -65 to $-70 \mathrm{j} . / \mathrm{kg}$. } \\
\hline & & & $\begin{array}{c}\text { Coeff- } \\
\text { cient of } \\
\text { varia- } \\
\text { tion }\end{array}$ & $\begin{array}{l}\text { Stand- } \\
\text { ard } \\
\text { devia- } \\
\text { tion }\end{array}$ & $\begin{array}{l}\text { Average } \\
\text { reading }\end{array}$ & $\begin{array}{c}\text { Coeffi- } \\
\text { cient of } \\
\text { varia- } \\
\text { tion }\end{array}$ & $\begin{array}{l}\text { Stand- } \\
\text { ard } \\
\text { devia- } \\
\text { tion }\end{array}$ & $\begin{array}{l}\text { Average } \\
\text { reading }\end{array}$ & $\begin{array}{c}\text { Coeffi- } \\
\text { cient of } \\
\text { varia- } \\
\text { tion }\end{array}$ & $\begin{array}{l}\text { Stand- } \\
\text { ard } \\
\text { devia- } \\
\text { tion }\end{array}$ & $\begin{array}{l}\text { Average } \\
\text { reading }\end{array}$ \\
\hline & Number & Number & Percent & & Ohms & Percent & & Ohms & Percent & & Olims \\
\hline $1^{2}$ & 25 & 100 & 11.0 & 50 & 453 & 14.1 & 93 & 659 & 13.3 & 105 & 700 \\
\hline $2^{2}$ & 20 & 80 & 9.4 & 45 & 482 & 11.9 & 76 & 636 & 11.8 & 91 & 768 \\
\hline $3^{2}$ & 10 & 40 & 6.1 & 31 & 500 & 11.4 & 86 & 759 & 20.8 & 199 & 958 \\
\hline $4^{2}$ & 10 & 40 & 14.1 & 67 & 475 & 35.4 & 303 & 855 & 42.4 & 446 & 1,052 \\
\hline $5^{2}$ & 5 & 20 & 4.7 & 40 & 845 & 5.0 & 48 & 954 & 4.6 & 49 & 1,058 \\
\hline $6^{2}$ & 5 & 20 & 8.4 & 35 & 420 & 12.5 & 69 & 555 & 8.0 & 51 & 734 \\
\hline $7^{3}$ & 15 & 60 & 19.4 & 109 & 561 & 19.5 & 113 & 581 & 20.0 & 121 & 600 \\
\hline $8^{3}$ & 25 & 100 & 22.3 & 108 & 486 & 24.2 & 119 & 492 & 23.6 & 123 & 523 \\
\hline $9^{2}$ & 10 & 40 & 5.1 & 36 & 705 & 8.7 & 93 & 1,073 & 13.4 & 178 & 1,331 \\
\hline $10^{2}$ & 24 & 96 & 9.6 & 31 & 320 & 17.3 & 99 & 574 & 19.3 & 158 & 821 \\
\hline $11^{2}$ & 12 & 48 & 6.2 & 20 & 317 & 12.6 & 69 & 545 & 12.9 & 101 & 782 \\
\hline $12^{2}$ & 11 & 44 & 13.1 & 41 & 312 & 25.7 & 104 & 405 & 31.3 & 181 & 577 \\
\hline $13^{2}$ & 10 & 40 & 17.2 & 56 & 323 & 22.6 & 78 & 343 & 15.1 & 58 & 380 \\
\hline
\end{tabular}

1 Unit number corresponds with description number, pp. 352-3.

2 Units constructed in the laboratory.

${ }^{3}$ Bouvoucos blocks, impregnated and not impregnated, 7 and 8 , respectively.

TABLE 2.-Effect of external contact on the resislance reading at saturation of various types of electrical-resistance units

\begin{tabular}{c|c|c|c}
\hline \multirow{2}{*}{ Identification No.t } & \multicolumn{2}{|c|}{ Reading } & $\begin{array}{c}\text { Reduction in resistance } \\
\text { reading }\end{array}$ \\
\cline { 2 - 3 } & Water & Air & Percent \\
\cline { 2 - 3 } 2 & Ohms & Ohms & 10.9 \\
5 & 490 & 550 & 51.1 \\
7 & 440 & 900 & 19.6 \\
9 & 370 & 450 & 18.8 \\
11 & 560 & 690 & - \\
12 & 350 & 350 & .02 \\
\hline
\end{tabular}

\footnotetext{
1 Units are described, pp. 352-3.
} 
FINAL BTUDY

Table 4 indicates the electrical-resistance readings of the moisture plaster blocks with decreasing water-potential values at the air-porous cup inter-

TABLE 3.-Relative sensitivity in the high-block water-potential range of the soil-moisture blocks included in the preliminary study

\begin{tabular}{c|c|c|c|c}
\hline & \multicolumn{3}{|c}{ Sensitivity } \\
\cline { 2 - 5 } Identification No.1 & \multicolumn{2}{|c|}{ Rate of increase- } & Regression coefficient & $\begin{array}{c}\text { Correlation } \\
\text { coeficient }\end{array}$ \\
\cline { 2 - 5 } & $\begin{array}{c}\text { To around } \\
\text { j./kg. }\end{array}$ & $\begin{array}{c}\text { To around } \\
\text { j./kg. }\end{array}$ & & \\
\hline & Percent & Percent & & Percent \\
& 45.5 & 74.4 & 0.104 & 84 \\
$1^{2}$ & 32.0 & 59.3 & .064 & 78 \\
$2^{2}$ & 3.6 & 8.0 & .010 & 3 \\
$7^{3}$ & 1.2 & 7.6 & .019 & 5 \\
$8^{3}$ & 43.7 & 88.8 & .104 & 90 \\
$9^{2}$ & 79.4 & 156.6 & .161 & 81 \\
$10^{2}$ & & & & \\
\hline
\end{tabular}

1 Units are described, pp. 352-3.

3 Units constructed in the laboratory.

s Bouyoucos blocks, impregnated and not impregnated, Nos. 7 and 8, respectively

TABLE 4.-Electrical-resistance reading and relative sensitivity (regression slope). of various types of soil-moisture blocks at decreasing water-potential values obtained from a centrally located tensiometer, when bolh blocks and tensiometer were subjected to the drying power of the air

\begin{tabular}{c|r|r|r|r|r|r}
\hline \multirow{2}{*}{ Block type } & \multicolumn{3}{|c|}{ Tensiometer water potential (ohms) in j./kg. indicated } & \multirow{2}{*}{$\begin{array}{c}\text { Slope of regres- } \\
\text { sion line }\end{array}$} \\
\cline { 2 - 5 } & \multicolumn{1}{|c|}{-14} & -23 & -35 & -50 & -66 & \\
\hline 1 & 710 & 780 & 880 & 1,010 & 1,070 & 0.0072 \\
2 & 710 & 710 & 730 & 790 & 850 & .0028 \\
3 & 820 & 880 & 1,040 & 1,260 & 1,310 & .0105 \\
4 & 700 & 890 & 1,140 & 1,420 & 1,540 & .0166 \\
5 & 1,080 & 1,240 & 1,430 & 1,670 & 1,800 & .0148 \\
6 & 850 & 870 & 890 & 930 & 960 & .0021 \\
\hline
\end{tabular}

1 Block type No. is described, pp. 352-3.

face of a tensiometer surrounded by the blocks included in the final study. The blocks and the tensiometer were allowed to dry from saturation by air maintained uniform inside a small compartment by minimizing the wind movement.

The slopes obtained by linear-regression analysis, when plotting electrical resistance reading of the blocks in ohms $v s$. block water-potential in 


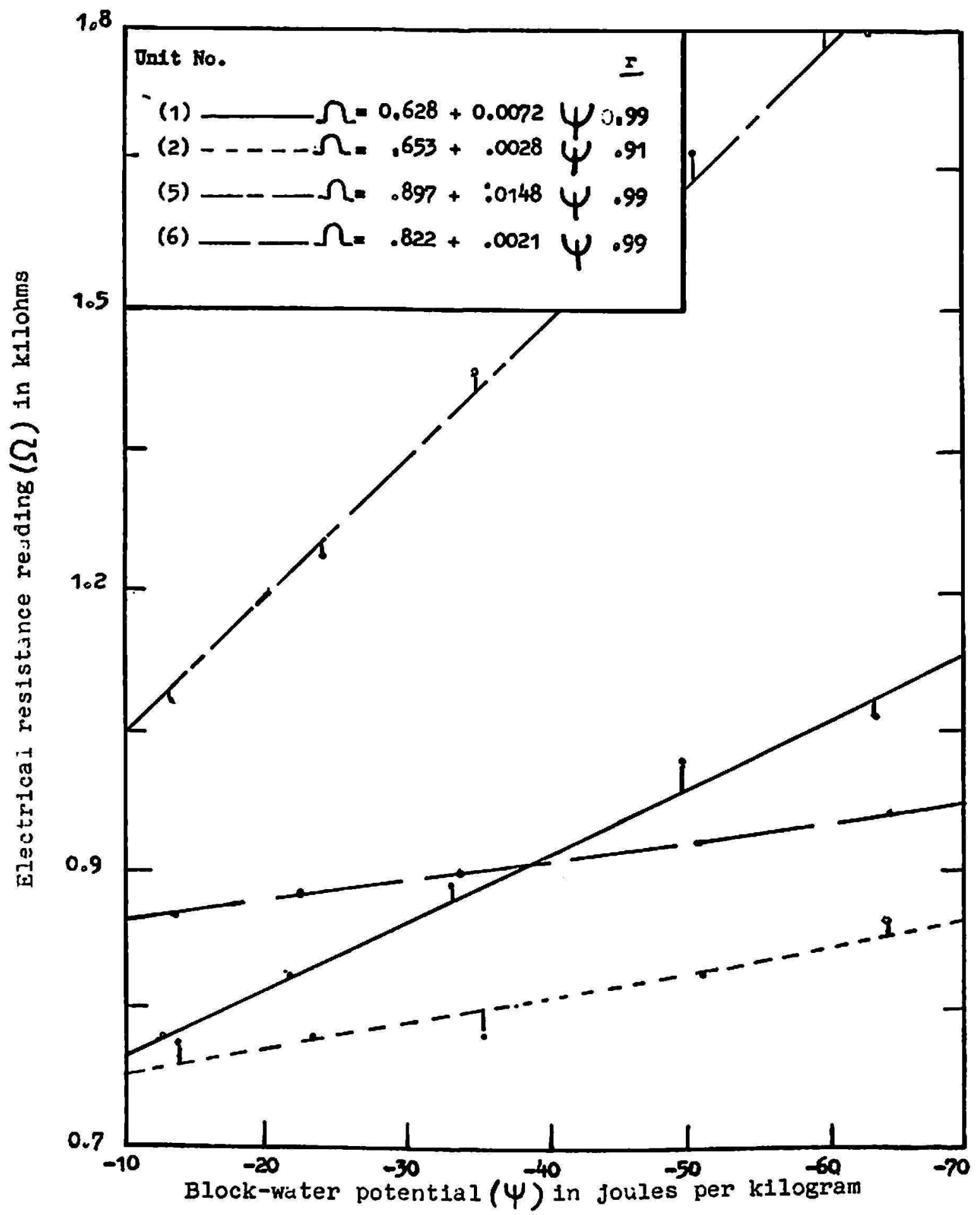

Fra. 1.-Electrical-resistance readings of rectangular soil blocks, indicating their sensitivity to moisture changes within them when in contact with air.

joules/kilogram is also presented in table 4 and indicated graphically in figures 1 and 2, for the rectangular and cylindrical blocks, respectively. These slopes were obtained for the wet range of soil moisture covered by tensiometers. In this range the response of electrical resistance to water potential can be considered to be linear. 


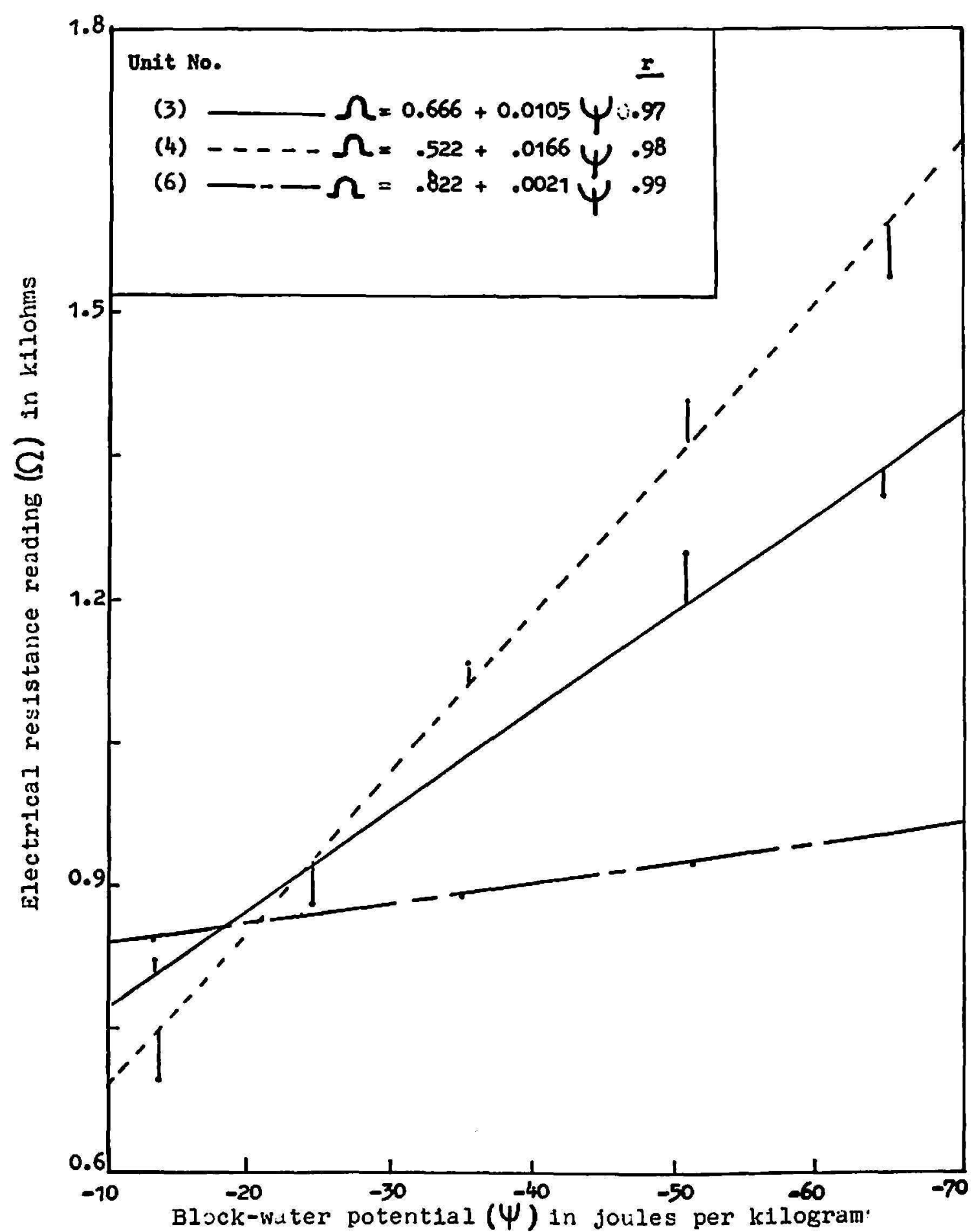

FIa. 2.-Electrical-resistance readings of cylindrical soil blocks, indicating their sensitivity to moisture changes within them when in contact with air. Block type 6 is a rectangular unit plotted here for comparison.

It is apparent that the moisture blocks made with Hydrocal B-11 as matrix material are more sensitive to the drying power of the air than the Bouyoucos blocks, or the laboratory-constructed units made with gypsum molding plaster. This sensitivity appears to increase with the water pro- 
portion in the mix for Hydrocal B-11 cylindrical constructed blocks (types 3 and 4) but not so for gypsum casting-plaster blocks (types 2 and 6). Of the rectangular blocks made with Hydrocal B-11, those made with platinized-nickel rod electrodes (type No. 5) appeared to be more sensitive than when the same blocks were made with stainless steel screen electrodes.

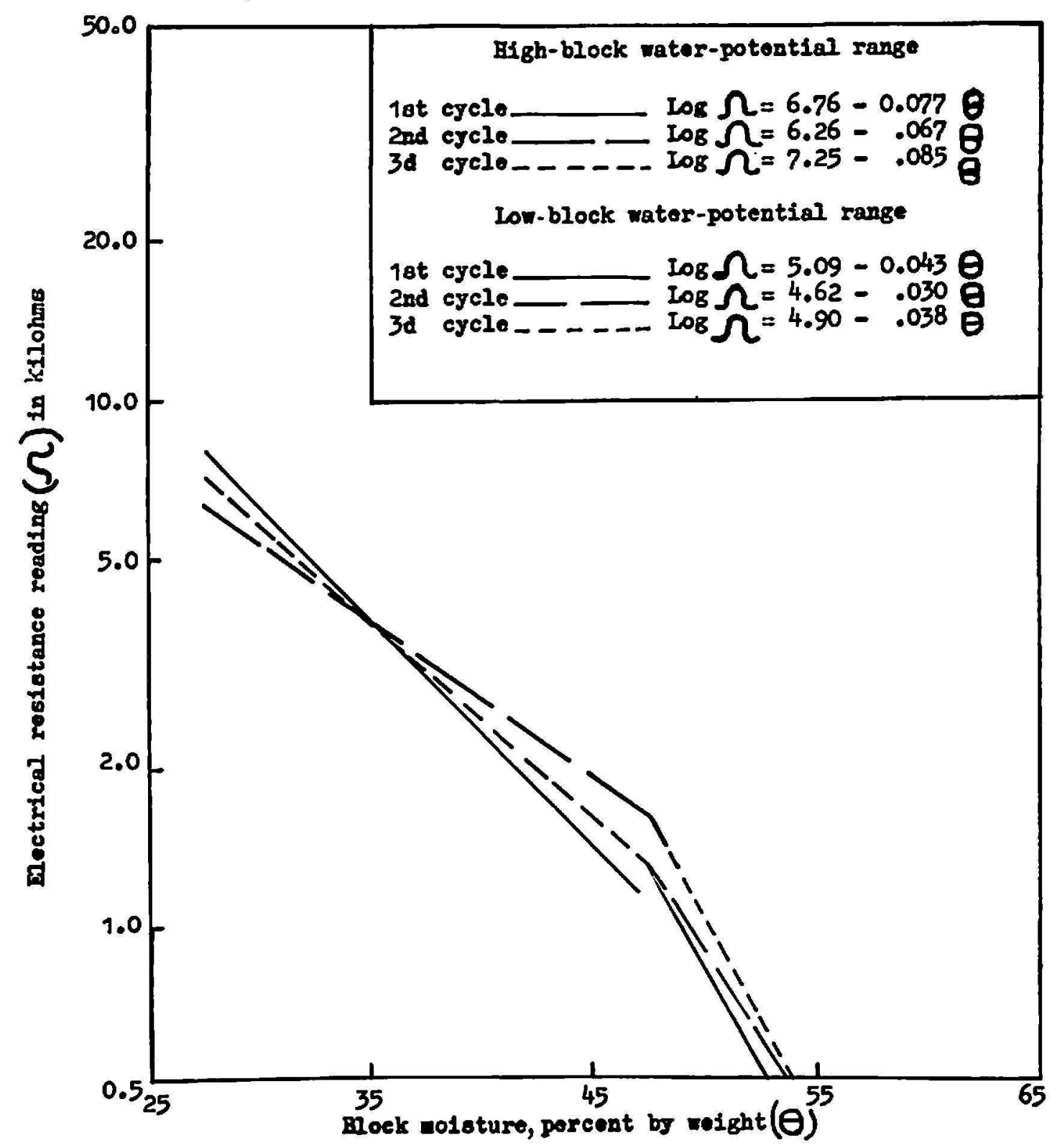

FIG. 3.-Electrical-resistance readings of block type 1 when subjected to 3 desorption cycles in the high- and in the low-block water-potential range.

Block types 1, 4, and 5 made with Hydrocal B-11 plaster, which appeared to be the most sensitive with decreasing block water potential, were further compared to block type 6 (Bouyoucos block) along a wider range of moisture content of the blocks.

Figures $3,4,5$, and 6 present the slopes obtained by linear regression 
analysis when the log of electrical resistance reading of the blocks is related to their moisture content for three desorption cycles. The analysis was carried out separately for moisture contents of the blocks at high and at low block water potential values. The breakpoint between these two

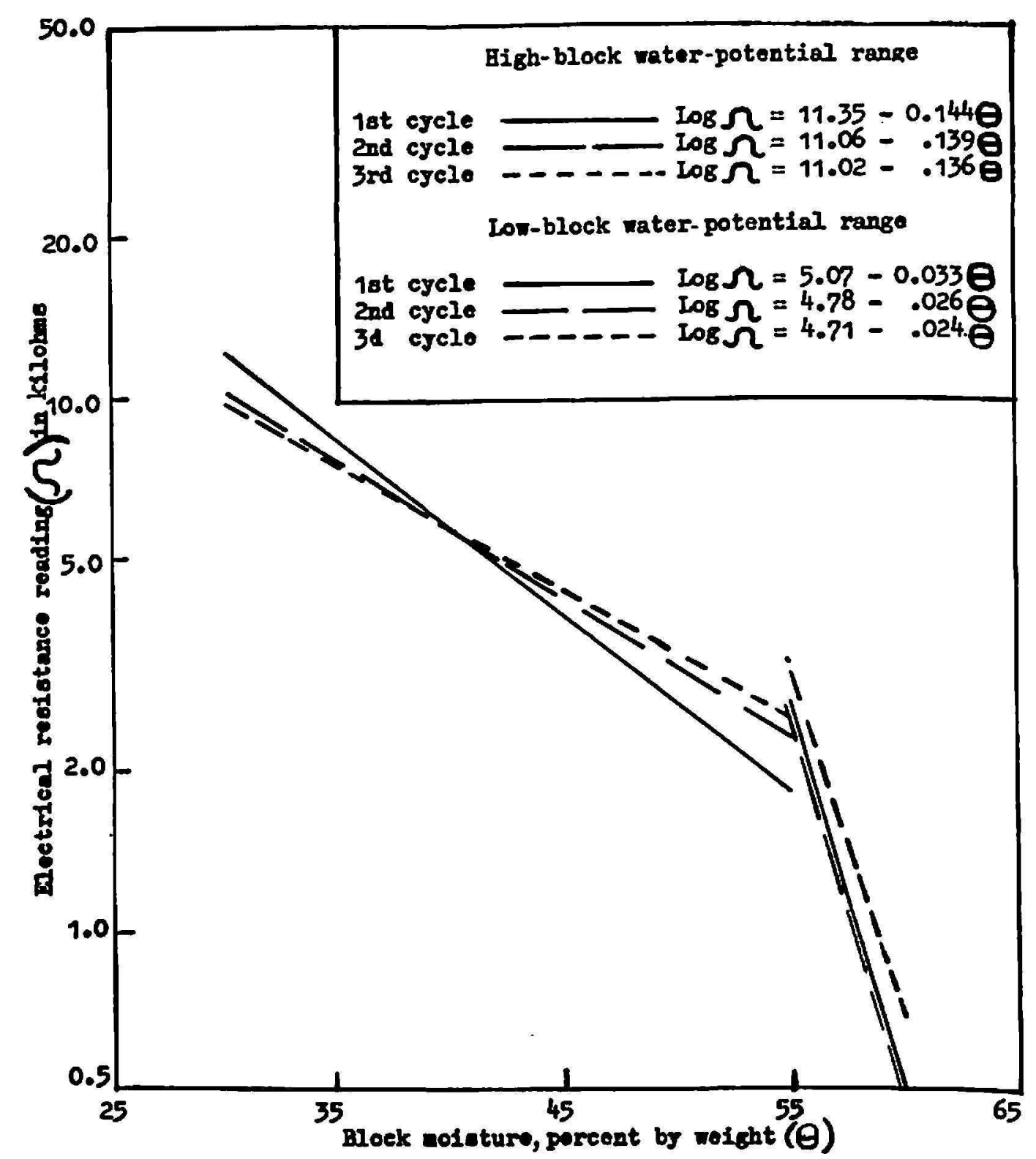

Fic. 4.-Electrical-resistance readings of block type 4 when subjected to 3 desorption cycles in the high- and in the low-block water-potential range.

ranges of block moisture content was taken at the electrical-resistance reading of the blocks corresponding to the approximate lower limit of reliable water-potential reading given by the tensiometer in the previous study on block sensitivity ( -65 to $-70 \mathrm{j} . / \mathrm{kg}$.). This time a logarithmic, instead of a natural scale, was used to correlate electrical-resistance readings of the blocks $v s$. the block moisture content (natural scale). This is because changes 
in electrical resistance of the blocks become exponential in nature as the block water-potential decreases. The object of repeating these studies through three desorption cycles is to evaluate the precision of the blocks in addition to evaluating their sensitivity once more.

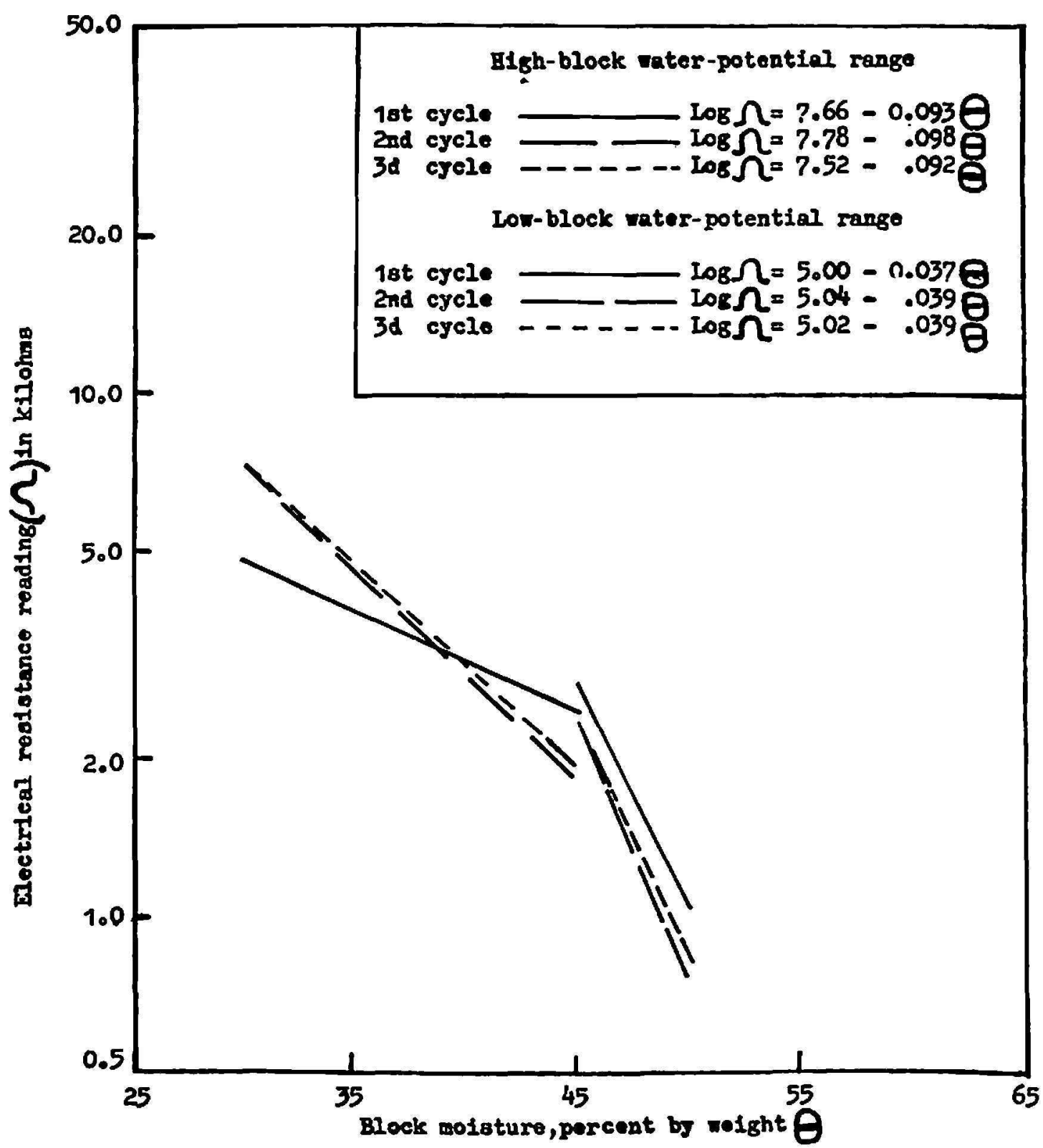

FIG. 5.-Electrical-resistance readings of block type 5 when subjected to 3 desorption cycles in the high-and in the low-block water-potential range.

By running an analysis of covariance it was attempted to evaluate the precision of the most sensitive blocks by determining whether one regression line could be used to represent all the observations, pooling together the regression data corresponding to the three desorption cycles. From the $F$ values indicated on table 5 for the high-block water-potential range, the hypothesis that one regression line can be used to represent all the ob- 
servations may be rejected, assuming a 1-percent risk. For the low-block water-potential range we are unable to reject the one-regression-line hypothesis for block types 1,4 , and 5, even assuming a 5-percent risk. The

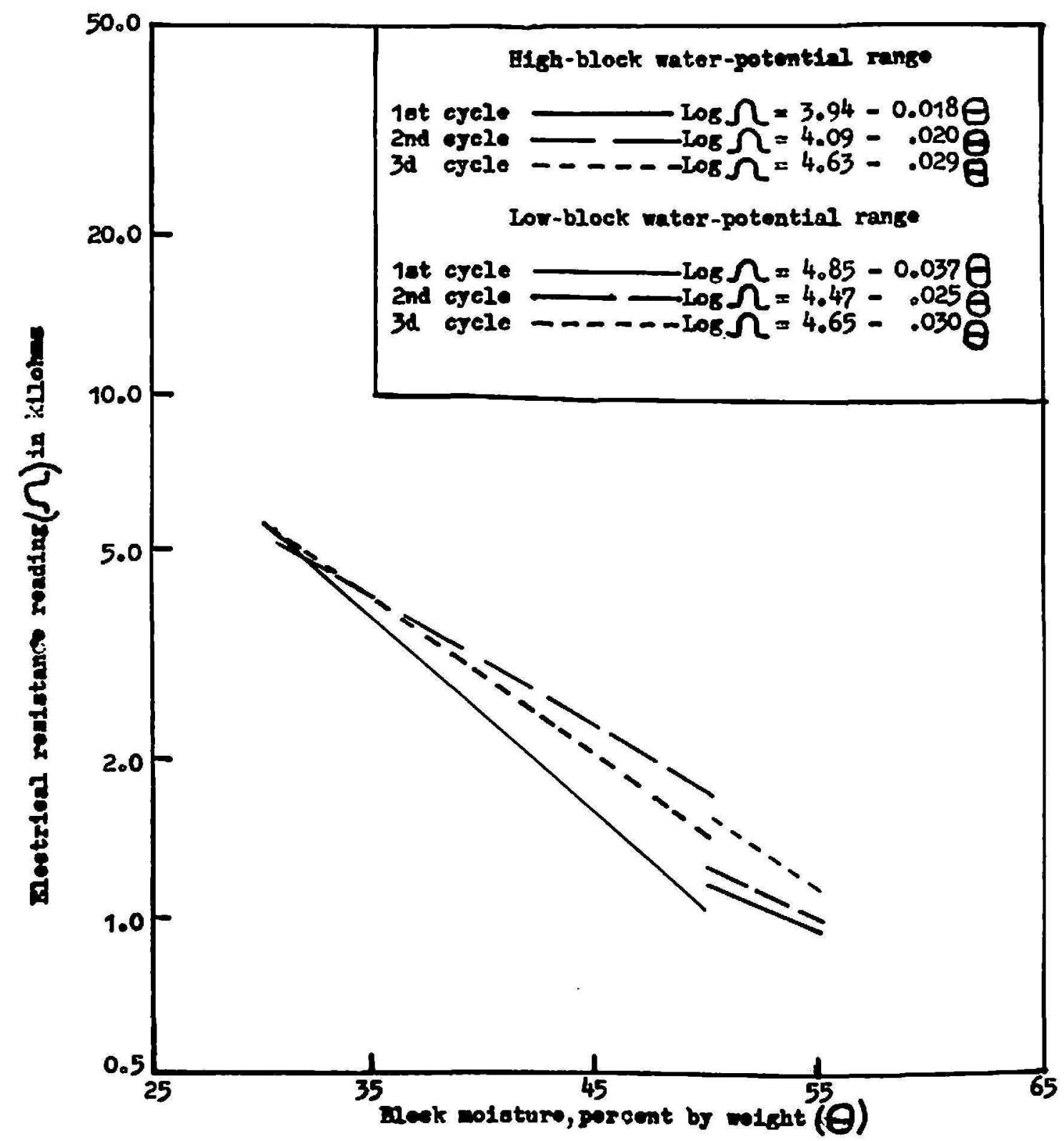

FIG. 6.-Electrical-resistance readings of block type 6 when subjected to 3 desorption cycles in the high-and in the low-block water-potential range.

$F$ value obtained for Bouyoucos block (type 6 ) is greater than $F, 0.01$ $(2,7)$ and, therefore the one-regression-line hypothesis may also be rejected for this block type at the low water-potential range.

A further attempt was made to investigate the reason for rejecting the null hypothesis that one regression line can be used to represent all the observations of three desorption cycles in the high-block water-potential 
TABLE 5.-Relative precision of different lypes of blocks, estimaled by pooling into 1 regression line the regression data corresponding to 3 desorption cycles for each type of block

\begin{tabular}{|c|c|c|c|c|c|c|c|c|}
\hline \multirow{2}{*}{$\begin{array}{c}\text { Block type } \\
\text { No.1 }\end{array}$} & \multicolumn{4}{|c|}{ High-block water-potential range } & \multicolumn{4}{|c|}{ Low-block water-potential range } \\
\hline & $\begin{array}{l}\text { Degrees } \\
\text { of } \\
\text { freedom }\end{array}$ & $\begin{array}{l}\text { Sum of } \\
\text { squares }\end{array}$ & $\begin{array}{l}\text { Miean } \\
\text { squares }\end{array}$ & $\underset{\text { value }}{F}$ & $\begin{array}{l}\text { Degrees } \\
\text { of } \\
\text { freedom }\end{array}$ & $\begin{array}{l}\text { Sum of } \\
\text { squares }\end{array}$ & $\begin{array}{c}\text { Mean } \\
\text { square }\end{array}$ & $\underset{\text { value }}{F}$ \\
\hline 1 & 9 & 0.0033 & 0.000366 & $13.11^{* *}$ & 7 & 0.0079 & 0.0011 & 4.00 \\
\hline 4 & 9 & .0117 & .0013 & $43.77^{* *}$ & 7 & .0072 & .0010 & 3.10 \\
\hline 5 & 9 & .0011 & .0001 & $73.00^{* *}$ & 6 & .0032 & .0005 & 3.80 \\
\hline 6 & 9 & .0005 & .00006 & $26.66^{* *}$ & 7 & .0035 & .0005 & $16.80^{* *}$ \\
\hline
\end{tabular}

${ }^{1}$ See pp. 352-3.

2 ** Significant to 1-percent level. F.01 $(2,9)=8.02, F .01(2,7)=9.55$, and F.01 $(2,6)=10.92$.

TABLE 6.-Relalive precision and sensitivity of different types of blocks, as indicated by the " $F$ " values oblained in lesting the null hypothesis $\beta_{1}=\ldots=\beta k$, and by the mean values of $\beta$, respectively

\begin{tabular}{|c|c|c|c|c|c|}
\hline \multirow{2}{*}{ Block type No.1 } & \multicolumn{3}{|c|}{ Desorption cycle } & \multirow{2}{*}{$\begin{array}{c}\text { Precision: } \\
F \\
\text { valuc }\end{array}$} & \multirow{2}{*}{$\begin{array}{c}\text { Sensitivity: } \\
\text { mean }\end{array}$} \\
\hline & 1st. & 2nd. & $3 d$. & & \\
\hline
\end{tabular}

High-block water-potential range

\begin{tabular}{l|c|c|c|c|c}
\hline & $\beta$ & $\beta$ & $\beta$ & & $\beta$ \\
1 & -0.0769 & -0.0665 & -0.0849 & 0.82 & -0.0761 \\
4 & -.1439 & -.1394 & -.1363 & .08 & -.1399 \\
5 & -.0928 & -.0978 & -.0919 & .50 & -.0942 \\
6 & -.0175 & -.0199 & -.0289 & 1.67 & -.0221 \\
\hline
\end{tabular}

Low-block water-potential range

\begin{tabular}{l|l|l|l|l|l}
\hline 1 & -0.0431 & -0.0298 & -0.0379 & $5.27^{*}$ & -0.0369 \\
4 & -.0330 & -.0258 & -.0240 & $5.17^{*}$ & -.0276 \\
5 & -.0376 & -.0392 & -.0385 & .05 & -.0384 \\
6 & -.0367 & -.0245 & -.0299 & $11.40^{* *}$ & -.0304 \\
\hline
\end{tabular}

${ }^{1}$ See pp. 352-3.

$2 *$ Significant at the 5-percent level. F.05 $(2,7)=4.74$. ** Significant at the 1percent level. F.01 $(2,9)=8.02$.

range as a measure of the precision of the blocks. The null hypothesis that the three regression coefficients corresponding to the three desorption cycles (figs. 3, 4, and 5) are equal was established. From the $F$ values indicated in table 6 we are unable to reject this hypothesis in the high-block waterpotential range for all block types studied. At the low-block water-potential range the hypothesis is rejected at the 1-percent level of significance for 
the Bouyoucos block, and at the 5-percent level for block types 1 and 4 . Block type 4 appeared to be the most sensitive and precise in the high-block water-potential range. Block type 5 excelled type 4 somewhat in precision and sensitivity, when the whole range of block water-potential is considered.

In an effort to explain differences is sensitivity among the different types of blocks included in the final study, the percentage of moisture released by the blocks for the time interval that it took a tensiometer to lower its water potential from -10 to $-65 \mathrm{j} . / \mathrm{kg}$. was determined while both blocks and the tensiometer were subjected to the same evaporative demands. The results are shown in table 7, and are given as the mean of three blocks for two desorption cycles. Table 7 indicates that the block types made with Hydrocal B-11 and with greater proportion of water to plaster in the

TABLE 7.-Moisture percenlage released by different types of blocks while subjected to the same evaporative demands as a centrally located tensiometer

\begin{tabular}{|c|c|c|c|c|c|}
\hline \multirow{2}{*}{ Block type No.1 } & \multicolumn{3}{|c|}{ Mean moisture (percent) a t- } & \multicolumn{2}{|c|}{$\begin{array}{l}\text { Moisture (percent) } \\
\text { released (rom- }\end{array}$} \\
\hline & $\stackrel{-10}{\mathrm{j} . / \mathrm{kg}}$ & j./kg. & j./kg. & $\begin{array}{c}-10 \text { to }-35 \\
\mathrm{j} . / \mathrm{kg} .\end{array}$ & $\begin{array}{c}-10 \text { to }-65 \\
\text { j. } / \mathrm{kg} .\end{array}$ \\
\hline 1 & 47.2 & 46.1 & 44.9 & 1.1 & 2.3 \\
\hline 2 & 58.1 & 57.1 & 55.7 & 1.0 & 2.4 \\
\hline 3 & 47.3 & 46.1 & 44.6 & 1.2 & 2.7 \\
\hline 4 & 58.3 & 56.8 & 55.0 & 1.5 & 3.3 \\
\hline 6 & 52.9 & 52.0 & 50.7 & .9 & 2.2 \\
\hline
\end{tabular}

${ }^{1}$ See pp. 352-3.

mix (block type 4) are characterized with the highest rate of water transfer across the block along the high block-water-potential range. The higher rate of water transfer characteristics of Hydrocal B-11 over gypsum molding plaster is evident. Even with a lower ratio of water to plaster in the mix the rate of moisture transfer across B-11 plaster was greater.

\section{DISCUSSION}

Hydrocal B-11 appears to be a more desirable porous material than gypsum molding plaster with respect to moisture-release characteristics. This is apparently the case for block types 3 and 4 as compared to block type 2 and the Bouyoucos block (type 6.) The sensitivity of the blocks made with Hydrocal B-11 plaster, in response to the evaporative demand of the air, and as exhibited by the electrical-resistance changes of the block with time, was in all cases greater than that exhibited by blocks made with gypsum molding plaster. This greater sensitivity was exhibited by the B-11 plaster blocks, both in the preliminary and in the final studies, and, under 
the experimental conditions, held irrespective of the proportion of water to plaster used in the mix.

Increasing the proportion of waler to plaster in the mix was apparently effective in increasing the sensitivity of Hydrocal B-11 blocks, but not so in gypsum molding-plaster blocks. The explanation of this difference in performance between the two kinds of plaster may be the greater increase in water-holding capacity of Hydrocal B-11 blocks over gypsum moldingplaster blocks as the ratio of water to plaster in the mix is increased. While Hydrocal B-11 plaster blocks underwent an increase of 10.7 percent moisture by increasing the water-plaster ratio from 0.6 to 0.8 , at a block waterpotential of around $-10 \mathrm{j} . / \mathrm{kg}$., gypsum molding-plaster blocks increased only 5.2 percent in moisture by increasing the water-plaster ratio from 0.66 to 1 at approximately the same block water-potential. The water-holding capacity of Hydrocal B-11 blocks with 60 and 80 percent of water, at -10 $\mathrm{j} . / \mathrm{kg}$., was 47.3 and 58.0 percent, respectively; that of gypsum moldingplaster blocks with 66 and 100 percent of water, and at the same block water potential was 52.9 and 58.1 percent, respectively. Bouyoucos (4) reported that the water-holding capacity of gypsum-plaster blocks at saturation increased from 32 to 57 percent when the water percentage of the blocks was increased from 66 to 100 .

The precision of the blocks is another factor of major importance. It may be expected that moisture blocks gain in sensitivity at the risk of losing in precision. It appears from the experimental results of this study that the lack of precision of the blocks along the high-block water-potential range is not the result of inconsistency in sensitivity with repeated desorption cycles. The analysis of covariance implies that there is significant cause to reject the null hypothesis that one regression line can represent all the observations of three drying cycles along the high-block water-potential range. However, further analysis with the same technique indicates that it cannot be concluded that the regression coefficients (slopes) for each desorp. tion cycle in the high-block water-potential range of all moisture blocks studied are different. Similarity between the regression coefficients appeared to characterize particularly the Hydrocal B-11 laboratory-constructed blocks in the low-block water-potential range, and especially of block type 5 in both high and low block-water-potential ranges.

It is interesting to note that, although cylindrical blocks appear to have the highest moisture-transfer rate in percentage of moisture released between two given block water-potential values, the geometrical configuration of the blocks does not appear to be an explanation. The ratio of surface area to volume of the block is $11 / 2$ times greater for the rectangularshaped blocks than for the cylindrical blocks. The greater hydraulic conductivity of cylindrical blocks results, irrespective of the water:plaster ratio. 
However, the greater the water:plaster ratio of Hydrocal B-11 blocks, the higher the moisture transfer-rate of the block. This increased hydraulic conductivity does not appear to be evident for gypsum molding plaster under the presently used laboratory methods and procedures.

In a recently concluded irrigation experiment with tobacco, cylindrical Hydrocal B-11 plaster blocks, made with a water:plaster ratio of 0.8 , were used to determine when to start and when to stop an irrigation. The block water-potential of a unit buried at 4 inches was used to determine when to start the irrigation. Another located at 16 inches was used to decide when to stop the irrigation. This instrumentation appeared to work quite satisfactorily in the establishment of irrigation regimes. The deeper block seemed to attain equilibrium with surrounding soil fast enough to prevent excessive water application. Although energy considerations rather than water volume, were used as basis of the irrigation regime, there seemed to be reasonable agreement between the amount of water applied and the apparent soil-water deficit before irrigations.

\section{SUMMARY}

An attempt was made to evaluate the intrinsic performance of plaster electrical-resistance units, independently of any influence of a surrounding soil. Hydrocal B-11 laboratory-constructed blocks appeared to excel gypsum molding-plaster blocks, including Bouyoucos blocks. This superiority of the Hydrocal B-11 blocks has been evaluated in terms of sensitivity and precision of the units. Platinized nickel-rod electrode blocks seemed to improve somewhat the sensitivity and the precision of the blocks. However, as this type of electrode will make the block more expensive, further investigation on the performance of this block type should be made. Hydrocal B-11 cylindrical blocks with a high water:plaster ratio (0.8) appear to be useful in irrigation scheduling if the data are interpreted in terms of energy relationships, rather than in terms of water-volume considerations.

\section{RESUMEN}

En estas pruebas se trató de evaluar el comportamiento intrínseco de bloques de resistencia eléctrica hechos de yeso, independientemente de cualquier influencia que pudiera ejercer el suelo en contacto con los bloques. Los bloques hechos en el laboratorio con Hidrocal B-11 superaron los que se moldearon con yeso, inclusive los bloques de Bouyoucos. La superioridad de los bloques de hidrocal B-11 se evaluó en términos de la sensitividad y precisión de las unidades. Los bloques con electrodos de níquel platinado parecieron mejorar un tanto en sensitividad y precisión. No obstante, como ese tipo de electrodo resultaría muy caro, debería investigarse más la actuación de dicho tipo de bloques. Los bloques cilíndricos de Hidrocal B-11 
hechos con una alta proporción de agua a yeso (0.8) parecen ser útiles para el riego regulado cuando los datos se interpretan en términos de las relaciones de energía, antes que en términos de volumen de agua.

\section{LITERATURE CITED}

1. Anderson, A. B., and Edlefsen, N. E., Laboratory study of the response of two and four electrode plaster of paris blocks as soil moisture indicators, Soil Sci. 53: 413-28, 1942.

2. Bourget, S. J., Elrick, D. E., and Tanner, C. B., Electrical resistance units for moisture measurements: Their moisture hysteresis, uniformity, and sensitivity, Soil Sci. 86: 298-304, 1958.

3. Bouyoucos, G. J., New type electrode for plaster of paris moisture blocks, Soil Sci. 78: 339-142, 1954.

4. - Soil moisture measurement improved, Agr. Eng. 48: 136-18, 1961.

5. Bouyoucos, G. J., and Mick, A. H., An Electrical Resistance Method for Continuous Measurement of Soil Moisture under Field Conditions, Mich. Agr. Expt. Sta. B. 172, 1940.

6. Capiel, M. A Comparison of Soil Moisture Measuring Devices and their Effectiveness in Predicting Irrigation Requirements in the Field, unpublished Master's thesis, Utah State Agr. Col., Logan, Utah, 1956.

7. Kelley, O. J., Hunter, A. S., Haise, H. R., and Clinton, H. H., A comparison of methods of measuring soil moisture under field conditions, J. Amer. Soc. Agron. S8: 759-84, 1946.

8. Perrier, E. R., and Marsh, A. W., Performance characteristics of various electrical resistance units and gypsum materials, Soil Sci. 86: 340-7, 1958.

9. Tanner, C. B., Abrahms, E., and Zebriski, J. C., Gypsum moisture block calibration on electrical conductivity in distilled water, Soil Sci. Soc. Amer. Proc. 19: $62-5,1948$.

10. Taylor, S. A., A comparison of general methods of field determination of soil moisture, Agr. Eng. $36:$ 654-9, 1955. 